\title{
Corrosion monitoring for underground and submerged concrete structures - examples and interpretation issues
}

\author{
R.B. Polder, W.H.A. Peelen \& G. Leegwater \\ TNO Built Environment and Geosciences, Delft, The Netherlands
}

\begin{abstract}
Since about 1980 Corrosion Monitoring Systems have been used in many concrete structures in aggressive environment worldwide. While these systems work properly in aboveground environment, some questions have arisen for submerged conditions, e.g. the outer sides of tunnels, piers in seawater or foundations in wet soil. One question concerns macro-cell formation between reinforcement in submerged concrete and in nearby aerated concrete, which might lead to severe corrosion for certain types or configurations of structures ("hollow leg"). In addition, in some cases, unexpected monitoring signals have been measured in submerged structures. The interpretation of electrochemical methods for monitoring the corrosion activity is not straightforward and new criteria have to be developed. This paper reports on an example of corrosion monitoring of an underground structure, the Green Heart Tunnel in The Netherlands. New criteria for interpretation of underground corrosion monitoring are proposed.
\end{abstract}

\section{INTRODUCTION}

The concept of reliability based service life design of concrete structures dates back to the 1980s (Siemes et al., 1985). DuraCrete (2000) proposed a practical methodology, which has become internationally accepted (fib, 2006). Important concrete infrastructure is increasingly being designed for long service life by modelling of degradations and probabilistic assessment of uncertainties (DuraCrete, 2000). Service life calculations in the design phase are necessarily based on modelling of degradation processes and aggressive loads and on testing of trial mixes for their resistance. In reality aggressive loads could be more severe or less severe than assumed in the design phase. Thus, monitoring of the performance could provide added value for the management of the structure.

Corrosion monitoring systems (CMS) for concrete structures have been used for some time with satisfactory results. However, in submerged structures unexpected signals have been observed and new criteria need to be developed (Raupach et al., 2007). The Green Heart Tunnel (GHT) is used as a test case.

In the particular case of the GHT, the durability performance aspects under consideration are the serviceability (water tightness) and safety (structural integrity) of the tunnel lining that may be impaired due to chloride induced corrosion of the outer reinforcement and carbonation at the inner reinforcement. The performance criterion refers to the initiation of reinforcement corrosion, which should be prevented during the service life with appropriate reliability. In the Service Life Design (SLD) this performance criterion was quantified using the DuraCrete models for chloride and carbonation induced corrosion.

The CMS was based on sensors to monitor the electrical resistance of concrete (indicating its humidity, related to carbonation) and the potential and galvanic current density of steel electrodes in the outer concrete skin (indicating depassivation due to chloride penetration). The choice of locations for monitoring sensors within the tunnel was determined by the pilot character of the project, i.e. a mix of practical and environmental (ground water chloride content) considerations.

Although state-of-the-art sensors were used, the application in an underground structure is atypical and questions exist on the interpretation of the results, as mentioned above. Supporting research was conducted on 'dummy' GHT concrete elements with built-in sensors, which were exposed to aggressive conditions in the laboratory. This paper aims at assessing the performance of the CMS in the tunnel and in particular the criteria to distinguish active/passive corrosion behaviour of the sensors.

\section{GREEN HEART TUNNEL AND ITS SERVICE LIFE DESIGN}

The Green Heart Tunnel (GHT) is a bored tunnel in the High Speed train Link (HSL) with a length of about $8.6 \mathrm{~km}$ and a single tube of $14 \mathrm{~m}$ inner diameter 


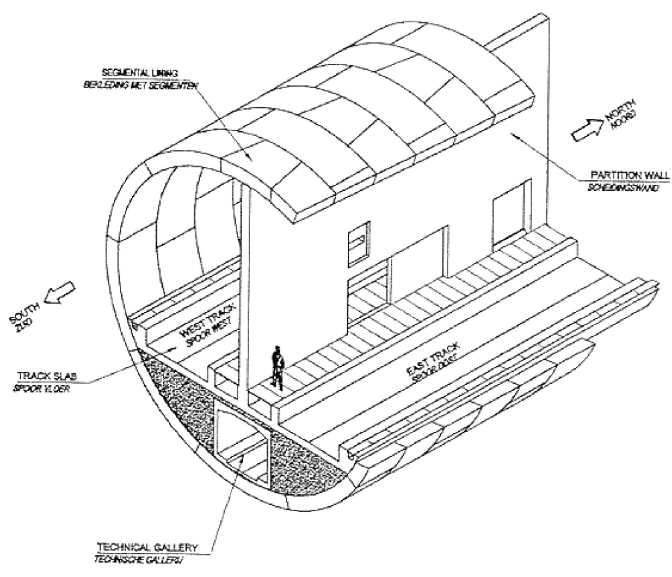

Figure 1. Impression of Green Heart high speed railway tunnel.

(Fig. 1). The lining consists of rings of ten precast reinforced concrete segments; a separation wall is cast in situ between the two tracks. The precast concrete composition was $450 \mathrm{~kg} / \mathrm{m}^{3}$ CEM III/A $52.5 \mathrm{~N}$ LA, aggregate of $28 \mathrm{~mm}$ and a w/c of 0.39 . The Client, ProjectOrganisatie HSL-Zuid, required a technical service life of 100 years. Deterioration mechanisms to be considered included reinforcement corrosion due to carbonation and chloride ingress. Chloride exposure should be based on seawater, considering possible leakage of ground water. The ground water is presently brackish (maximum c. $5 \mathrm{~g}$ of chloride ion per litre), but may become more saline in the future (supposedly c. $20 \mathrm{~g} / 1$ ). Models and input should be state-of-the-art, based on DuraCrete. Specific requirements were given: a maximum chloride diffusivity of $5^{*} 10^{-12} \mathrm{~m}^{2} / \mathrm{s}$, tested using the Rapid Chloride Migration (RCM) method (at 28 days). Various uncertainties turned up after the SLD was made. As the most relevant here, macro cell corrosion was identified as a potential threat, with increased corrosion rates due to galvanic coupling between depassivated bars on the outer side and passivated but well aerated bars on the inner side. Monitoring was thought a way to cope with uncertainties; however, a general lack of experience existed. Thus, a monitoring system was installed as a pilot project, which also included studying elements with sensors in the laboratory.

\section{MONITORING SYSTEM}

Two types of sensors from $\mathrm{S}+\mathrm{R}$ Sensortec $\mathrm{GmbH}$ were chosen: Multi Ring Electrodes (MRE) and Anode Ladders sensors (AL). MRE sensors measure concrete resistance from which moisture content can be derived. The present focus is on the AL sensors. They consist of six steel bars (further referred to as steps), embedded parallel to the concrete surface at different depths of about $10 ; 20 ; 30 ; 40 ; 50$ and $60 \mathrm{~mm}$. The steps are made of steel comparable to reinforcing steel and similar corrosion characteristics are assumed. Due to chloride ingress a profile will develop with higher chloride contents at the exterior of the elements. Over time, the critical chloride content for corrosion initiation will be exceeded for subsequent steps of the AL; consequently they will depassivate and start to corrode. A potential difference develops between an actively corroding step and the passive reinforcing cage. By monitoring the potential of a step versus the reinforcement, the onset of corrosion can be determined. Upon connecting the step and the reinforcement through a low-resistance ampere meter, the galvanic current between a step and the reinforcement can be measured as an indication of the macro-cell current. A high galvanic current indicates active corrosion. Moreover the electrical resistance between the subsequent steps can be measured and converted to a resistivity (cell constant about $0.1 \mathrm{~m}$ ). Measuring potential (open circuit) and galvanic current (short circuit) are mutually exclusive. Normally the circuit is open and steady state potential differences are monitored. Upon short circuiting, the galvanic current is non-steady state (decreasing with time) and thus the moment of measuring after closing the circuit is important. It should be realized that this also means that the galvanic currents observed are a strong overestimation of the real steady state corrosion current density. Sensortec recommends as the boundary between active and passive conditions a potential difference of $100 \mathrm{mV}$ and a current of $15 \mu \mathrm{A}$ (measured $5 \mathrm{~s}$ after short circuiting), corresponding to an average current density of about $10 \mathrm{~mA} / \mathrm{m}^{2}$. These values are further called "conventional criteria".

Two tunnel rings were provided with sensors. One ring had 20 MRE's embedded (both interior and exterior). In the second ring, nine elements were equipped with one AL in the exterior face and one MRE in the interior face, as sketched in Fig. 2. The AL elements were produced in September 2003 and installed in the tunnel in October 2003; after initial tests, regular in situ measurements were taken from February 2005.

\section{LABORATORY TESTS}

Dummy elements were produced as trial objects, one with three MRE's and one with one AL and one MRE (called AL dummy). After accepting them as successfully produced, they were placed outside without shelter. In 2004/2005, a test area of $0.3 \mathrm{~m} \times 0.4 \mathrm{~m}$ over the AL sensor in the AL dummy was exposed to salt water with $20 \mathrm{~g}$ chloride/ 1 for 180 days. Steel potentials, galvanic currents and concrete resistivities were measured periodically using the embedded sensors. After 180 days the solution was removed and 


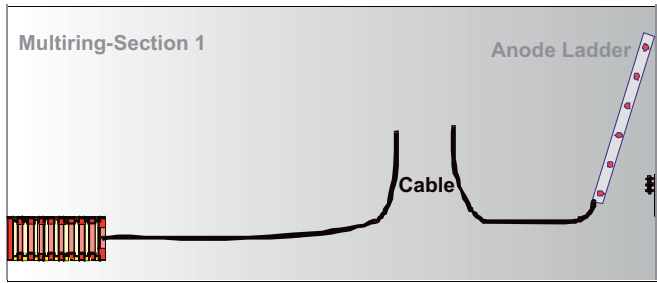

Figure 2. Principal cross section of element with Multi Ring Electrode (left, inside) and Anode Ladder (right, outside); salt ground water on right hand side.

Table 1. Summary of data measured in GHT for all steps in anode ladder sensors, versus reinforcement, February 2006; $\mathrm{a} \pm \mathrm{b}$ indicates mean \pm standard deviation; * suspect results.

\begin{tabular}{llc}
\hline Element & $\begin{array}{l}\text { Potential difference } \\
(\mathrm{mV})\end{array}$ & $\begin{array}{l}\text { Galvanic current } \\
\left(\mathrm{mA} / \mathrm{m}^{2}\right)\end{array}$ \\
\hline S01 & $-100 \pm 40$ & $0 \pm 10$ \\
R1 & $-330 \pm 5$ & $-80 \pm 10$ \\
R2 & $-330 \pm 30$ & $0 \pm 5$ \\
S04 & $-390 \pm 80$ & $-90 \pm 20$ \\
S06 & $-420 \pm 80$ & $-70 \pm 30$ \\
S07 & $-250 \pm 20$ & $-50 \pm 20$ \\
S08 & $-440 \pm 90$ & $-70 \pm 20$ \\
S09 & $-410 \pm 80$ & $-70 \pm 20$ \\
mean & $-290 \pm 40$ & $-47 \pm 13$ \\
\hline
\end{tabular}

cores were taken and analysed for chloride penetration. Other cores were subjected to salt water exposure in the laboratory and analysed for chloride penetration. Before the exposure, concrete resistivity was measured on the surface using both Wenner and two-point methods (Polder, 2001). In 2006, another series of exposure testing was started. Firstly all potentials, resistances and galvanic currents were measured after more than a year with only normal exposure to outside weather. Then the surface was exposed to water for 35 days and subsequently to saturated $\mathrm{NaCl}$ solution $(360 \mathrm{~g} / \mathrm{l}$, still running). Potentials, resistances and galvanic currents were measured periodically.

\section{RESULTS AND DISCUSSION}

\subsection{Measurements in the tunnel}

In Table 1, potential difference and galvanic current results measured in the tunnel are summarised. Measured values differed statistically significantly between elements, but showed an increasingly negative trend in time. The overall mean values early 2006 for steps at all depths were about $-300 \mathrm{mV}$ and about $50 \mathrm{~mA} / \mathrm{m}^{2}$. This suggests by the conventional criteria for passive/active behaviour mentioned above, that steel depassivation had already occurred on a wide scale. In view of the short exposure and the relatively low chloride content of the ground water, this is highly unlikely. Critical evaluation of the criteria appeared necessary, which is discussed below.

\subsection{Dummy element testing}

Laboratory testing of the test area in the AL-dummy element during 180 days exposure to $20 \mathrm{~g} / 1 \mathrm{chlo}-$ ride solution and of cores taken before and after the exposure showed the following.

The Anode Ladder sensors clearly respond to salt water penetration; steel potentials become more negative, galvanic current densities increase and concrete resistivity drops, corresponding to penetration of water and chloride in space and time.

The penetration of water is faster than the penetration of chloride ions; apparently they are separated during transport. After 180 days of exposure, chloride ions have penetrated the concrete to depths of about $15 \mathrm{~mm}$ and water has penetrated $30-40 \mathrm{~mm}$.

Cores exposed to salt water in the laboratory show similar penetration of water and chloride as the test area. In cores that had been stored in $20^{\circ} \mathrm{C} 80 \% \mathrm{RH}$ before exposure, chloride surface contents were $0.65 \%$ by mass of cement in $5 \mathrm{~g} / 1$ chloride solution and $1.5 \%$ in $20 \mathrm{~g} / 1$ solution. These surface contents will probably increase over time. For various levels of water saturation and chloride concentration, apparent chloride diffusion coefficients after 180 days were in the range of 2 to $11^{*} 10^{-12} \mathrm{~m}^{2} / \mathrm{s}$.

The potential difference between the AL steps and the reinforcement ranged from -60 to $-600 \mathrm{mV}$, with a mean of $-325 \mathrm{mV}$; galvanic current density ranged from 0 to $-400 \mathrm{~mA} / \mathrm{m}^{2}$, mean $-100 \mathrm{~mA} / \mathrm{m}^{2}$.

Assuming $0.5 \%$ of chloride by mass of cement for the critical content, only the first step of the AL sensor at a depth of $10 \mathrm{~mm}$ may be supposed to have undergone corrosion initiation during 180 days of salt water exposure. The other steps should not have depassivated. For these steps, the electrochemical criteria suggest active behaviour, which is highly unlikely; consequently, the need revision.

The best criterion to distinguish between passive and active behaviour of the Anode Ladder steps is based on the galvanic current density, with a passive/active boundary of about $200 \mathrm{~mA} / \mathrm{m}^{2}$ of steel surface area. The potential difference to reinforcing steel does not provide a good criterion.

At $20^{\circ} \mathrm{C}$ and in the fog room the concrete resistivity of drilled cores was about $500 \Omega \mathrm{m}$ and in $20^{\circ} \mathrm{C}$ $80 \% \mathrm{RH}$ about $700 \Omega \mathrm{m}$, generally similar to surface measurements on the element.

The non-wetted side of the element showed a generally stable resistivity at intermediate levels 
$(1000-3000 \Omega \mathrm{m})$, indicating a moderate and relatively stable moisture content.

Further testing in 2006 on the element surface and then exposure to water for 35 days and subsequently to saturated $\mathrm{NaCl}$ solution $(360 \mathrm{~g} / \mathrm{l})$ for another 15 days showed the following.

Before water exposure (so in "atmospheric condition"), the outer step 1 showed a negative potential difference of $-200 \mathrm{mV}$ and a galvanic current of $-13 \mathrm{~mA} / \mathrm{m}^{2}$, both indicating active corrosion by the conventional criteria; other steps showed much smaller values, suggesting passive behaviour.

After 35 days of water exposure, step 1 potential was $-440 \mathrm{mV}$ and its galvanic current increased to $-165 \mathrm{~mA} / \mathrm{m}^{2}$; potential differences for steps 2 to 6 ranged from 0 to $-100 \mathrm{mV}$, galvanic currents from +2 to $-5 \mathrm{~mA} / \mathrm{m}^{2}$, suggesting passive behaviour. After another 15 days with saturated $\mathrm{NaCl}$, many potentials exceeded $-100 \mathrm{mV}$ and galvanic currents were $-700 \mathrm{~mA} / \mathrm{m}^{2}$ for step 1 and 0 to $-6 \mathrm{~mA} / \mathrm{m}^{2}$ for other steps;

\subsection{Interpretation of signals}

Interpreting the signals from the $\mathrm{AL}$ steps using the conventional criteria, only the data taken under atmospheric conditions appear to produce realistic results: step 1 corrodes, the other steps are passive. This makes sense assuming that the chloride profile measured in April 2005 (at the end of the 180 days exposure) has not significantly changed.

After 35 days of water exposure and another 15 days of saturated chloride exposure, the same steps produce quite different potentials and galvanic currents. In particular steps 2,3 and 6 have potentials that suggest active corrosion. It is possible that step 2 has undergone corrosion initiation, but it is unlikely that the corrosion conditions of steps 3 and 6 have changed dramatically in such a short time. The previous experiments have shown that the penetration of water is so quick that the water content at the steel changes in a few days to weeks. Apparently the measurements taken under different conditions with regard to wetting should be interpreted using different criteria and/or boundary values.

There is a mechanistic basis for such a change of interpretation. The potential of passive steel strongly depends on the presence of oxygen at the steel/concrete interface. Under water saturated (permanently submerged) conditions the potential may be as low as $-800 \mathrm{mV}$ (SCE) with a negligible corrosion rate (Arup, 1983; Bertolini et al., 2004) due to oxygen starvation. In our tests, the blast furnace slag cement may also have influenced the potentials. Under limited oxygen access, reduced substances in the slag (sulphides, low valence manganese species) may cause negative potentials without actual steel corrosion. Strongly negative potentials were also found in submerged slag cement concrete sheet piles, without active corrosion (Peelen \& Polder, 2004). Even in the (lower) splash zone of slag cement structures, low potentials can be found without actual corrosion (Rooij \& Polder, 2005). Under normal atmospheric conditions, in which the concrete and the steel are well aerated, normal passive potentials between +100 and $-100 \mathrm{mV}$ (SCE) develop in slag cement concrete, like in Portland cement concrete. As a working hypothesis, oxygen starvation may influence potentials and galvanic currents in submerged concrete in such a way that passive/active potential boundaries change. Oxidation of reduced species in slag may also contribute to the galvanic current.

From the previous experiments on the AL-dummy element it was suggested that the step-reinforcement potential was not a good criterion for distinguishing passive/active conditions. The conventional galvanic current boundary value was also not found suitable. Instead a galvanic current density of $200 \mathrm{~mA} / \mathrm{m}^{2}$ was proposed (corresponding to $300 \mu \mathrm{A}$ measured current) for very wet and/or submerged (slag) concrete. As discussed above, low oxygen availability may cause the potential to drop to negative values without actual corrosion initiation. Potentials as low as -600 to $-800 \mathrm{mV}$ (versus SCE) could develop without real depassivation ("imperfect passivation"). In a tunnel element which is submerged on one side and aerated on the other side, current is exchanged between connected steel bars and the potential of either group of bars will assume a mixed potential value between that of the non-aerated steel on the outer side and the aerated steel on the inner side. Attempts to calculate such potentials have been reported recently (Redaelli et al., 2006). For a free corrosion potential of $-600 \mathrm{mV}$ of non-aerated steel, an actively corroding bar on the outside has a potential of $-539 \mathrm{mV}$ (SCE) and a passive bar on the outside $-532 \mathrm{mV}$, while the (connected) steel in the inner side has a potential of $-173 \mathrm{mV}$ (free corrosion potential $+100 \mathrm{mV}$ ). In that study, the resistivity was rather low $(80 \Omega \mathrm{m}$ in wet conditions and $1000 \Omega \mathrm{m}$ in semi-dry conditions). The higher resistivity of the GHT case will have a limited effect on the calculated potentials, so the results can be used for our present analysis. It appears that both corroding and non-corroding bars can have very negative potentials under water-saturated and non-aerated conditions. In a tunnel, potentials of $-539 \mathrm{mV}$ (active) and $-532 \mathrm{mV}$ (passive) can hardly be distinguished. This can be taken as an explanation for the similarly negative potentials of active and passive ladder steps in the tunnel. In our laboratory experiments, oxygen access could be somewhat higher than in the tunnel, resulting in potentials in the range between -400 and $-700 \mathrm{mV}$. On the other hand, this explanation suggests that in the tunnel eventually all steel near the wetted side may assume negative potentials, including the reinforcement cage, even if true depassivation 
is absent. The potential difference between steps and reinforcement will then disappear. So far, this has not as yet occurred in the AL-dummy element (with supposedly better oxygen access than in the tunnel). The expectation is that in time, step-reinforcement potential differences will decrease, in particular in the tunnel. This proves again that potential differences cannot be a useful criterion in submerged conditions. It should be taken into account that reduced species in slag cement have not been considered in this discussion. If they are important, their effect will most likely support the analysis given here.

Regarding the absolute value of galvanic current density, the following observation is made. A current density of $200 \mathrm{~mA} / \mathrm{m}^{2}$ theoretically corresponds to a steel thickness loss of about $200 \mu \mathrm{m} /$ year. This would be an extremely high corrosion rate, which in our experience occurs rarely in practice. However, high current densities may exist for the mechanism of macrocell corrosion. It could be speculated that oxidation of the reduced slag components contributes to such high current densities in our case. Current decrease has been observed over connection times from less than a second to $30 \mathrm{~s}$. Longer connection times will expectedly produce lower galvanic current densities. In any case, to interpret galvanic currents in terms of corrosion rates, more work is needed. In particular measuring galvanic current while maintaining the connection for longer times would be valuable.

Based on the results and discussion presented, we propose that the (conventional) criteria for distinguishing active and passive steel in submerged concrete need to be modified. In aerated concrete, a potential difference between ladder steps and reinforcement cage of $100 \mathrm{mV}$ and a galvanic current density of $10 \mathrm{~mA} / \mathrm{m}^{2}$ may well indicate the passive/active boundary. Our experiments support that position. In very wet conditions (as in submerged concrete), the potential difference is no longer a useful criterion. Galvanic current density may be useful, but the boundary value must be increased. At present it appears that $200 \mathrm{~mA} / \mathrm{m}^{2}$ is a proper boundary between active and passive behaviour of steel electrodes (here AL steps) in submerged slag cement concrete. Due to the supposed influence of reduced species in the slag, this value may not necessarily apply to Portland cement concrete. Expectedly, however, the principle of modifying the criteria is the same for submerged Portland cement concrete structures.

\section{CONCLUSIONS}

From the measurements on the durability monitoring system in the GHT taken so far, it appears that all sensors produce correct signals in an electrical sense. Sensors, cabling and data readout of the original monitoring system function well. In November 2006, a new system with automated data recording and wireless readout was installed.

The most critical issue for the GHT CMS is the interpretation of signals from Anode Ladder steps in terms of corrosion initiation. The conventional criteria (potential difference and galvanic current) and boundary values $(100 \mathrm{mV}$ and $15 \mu \mathrm{A}$, respectively) produce doubtful results. For many sensor steps in the tunnel these criteria suggest corrosion initiation, while the local conditions most likely have not initiated corrosion. Experiments on the AL-dummy element under laboratory conditions have shown that probably passive steps exceed the conventional criteria, if the concrete surface over the steps is exposed to water and/or salt solution for a few weeks. This can be explained from the electrochemical behaviour of steel in water saturated concrete, in particular from the low availability of oxygen. Absence of oxygen depresses the potential to more negative values, even without corrosion inducing chloride levels; this condition may be termed imperfect passivation. Consequently, a modification of the criteria and boundary values is proposed. First, the potential should be no longer used as a criterion for distinction between (truly) active and passive behaviour. Second, the active/passive boundary value for the galvanic current is proposed to be set at $200 \mathrm{~mA} / \mathrm{m}^{2}$, corresponding to $300 \mu \mathrm{A}$. These values apply for water saturated (or at least very wet) slag cement concrete.

Based on the conclusions with regard to the electrical performance of the monitoring system and the modified interpretation, the Durability Monitoring System in the Green Heart Tunnel is concluded to perform well. It is expected that, using modified criteria and boundary values, signals can be interpreted properly with regard to chloride ingress and corrosion initiation. Once corrosion has initiated, macro cell corrosion is a significant mechanism. This allows drawing conclusions on the performance of the tunnel with regard to durability. Further work is underway to investigate the significance of monitoring results with regard to updating the original design service life of the tunnel.

\section{ACKNOWLEDGEMENTS}

The authors acknowledge the cooperation of HSLZuid with the work reported here and their permission to use the results. We thank in particular the supervision and discussions provided by Robert Jan Aartsen, Alain Kooiman, Kees Blom, Sander Lokhorst and Joost Gulikers who represented HSL-Zuid in various stages.

This study is part of National Programme Delft Cluster, project DC02.30 "Smart sustainable management of concrete structures" as Work Package 
02.33.21 "Technical integration and interpretation of monitoring results for maintenance management".

Finally, the authors acknowledge valuable discussions with European Federation of Corrosion Task Group members Michael Raupach (ibac), Birit Buhr Jensen, Ruth Sørensen, Thomas Frolund (COWI) and Oskar Klinghoffer and Peter Nygaard (FORCE) of a previous version of this paper.

\section{REFERENCES}

Arup, H., 1983, The mechanism of the protection of steel by concrete, Proc. Corrosion of Reinforcement in Concrete, ed. A.P. Crane, Society of Chemical Industry, 151-157

Bertolini, L., Elsener, B., Pedeferri, P., Polder, R.B. 2004 . Corrosion of Steel in Concrete: Prevention, Diagnosis, Repair, Wiley-VCH Verlag GmbH \& Co. KGaA, Weinheim, ISBN 3-527-30800-8, $392 \mathrm{p}$

DuraCrete, 2000, DuraCrete Final Technical Report R17, Document BE95-1347/R17, The European Union - Brite EuRam III, DuraCrete - Probabilistic Performance based Durability Design of Concrete Structures, CUR, Gouda fib, 2006, Model Code for Service Life Design, Task Group 5.6, fib Bulletin 34, Zurich

Peelen, W.H.A., Polder, R.B., 2004, Durability assessment of the concrete sheet piling for the new Dutch heavy-duty 'De Betuweroute' railway line, Corrosion Prevention \& Control, 11-16

Polder, R.B., 2001, Test methods for on site measurement of resistivity of concrete - A RILEM TC-154 Technical Recommendation, Construction and Building Materials, Vol. 15 (2-3), 125-132

Raupach, M., Polder, R.B., Frolund, T., Nygaard, P., 2007, Corrosion monitoring at submerged concrete structures macrocell corrosion due to contact with aerated areas?, Eurocorr07, Freiburg

Redaelli, E., Bertolini, L., Peelen, W., Polder, R., 2006, FEM-models for the propagation of chloride induced reinforcement corrosion, Materials \& Corrosion, Vol. 57, (8), 628-635

Rooij, M.R. de, Polder, R.B., 2005, Duurzaamheid mariene betonconstructies (Durability of marine concrete structures), Report 215, CUR, Gouda, in Dutch

Siemes, T., Vrouwenvelder, T., Beukel, A. van den, 1985, Durability of buildings: a reliability analysis, HERON, Vol. 30 (3), Delft, 2-48 